\title{
SCIENTIFIC REPORTS

\section{Corroboration and efficacy of Magneto-Fluorescent (NiZnFe/CdS) Nanostructures Prepared using Differently Processed Core}

\author{
Dipti Rawat, P. B. Barman \& Ragini Raj Singh $\mathbb{1}^{*}$ * \\ The selected and controlled preparation of core@shell nanostructures, which unite the multiple \\ functions of ferromagnetic $\mathrm{Ni}-\mathrm{Zn}$ ferrite core and $\mathrm{CdS}$ shell in a single material with tuneable \\ fluorescence and magnetic properties, have been proposed by the seed mediated aqueous growth \\ process. The shell particle thickness and core of nanostructures were precisely tuned. Current work \\ exhibits the comparative study of core@shell multifunctional nanostructures where core being \\ annealed at two different temperatures. The core@shell nanostructure formation was confirmed by \\ complementary structural, elemental, optical, magnetic and IR measurements. Optical and magnetic \\ characterizations were performed to study elaborative effects of different structural combinations \\ of core@shell nanostructures to achieve best configuration with high-luminescence and magnetic \\ outcomes. The interface of magnetic/nonmagnetic $\mathrm{NiZnFe}_{2} \mathrm{O}_{4} / \mathrm{CdS}$ nanostructures was inspected. \\ Unexpectedly, in some of the core@shell nanostructures presence of substantial exchange-bias \\ was observed in spite of the non-magnetic nature of CdS ODs which is clearly an "optically-active" \\ and "magnetically-inactive" material. Presence of "exchange-bias" was confirmed by the change in \\ "magnetic-anisotropy" as well as shift in susceptibility derivative. Finally, successful formulation of \\ stable and efficient core@shell nanostructures achieved, which shows no exchange-bias and shift. \\ Current findings suggest that these magneto-fluorescent nanostructures can be used in spintronics; and \\ drug delivery-diagnosis-imaging applications in nanomedicine field.
}

Nanostructures are found to be of great magnitude for the reason that of their vital properties, such as, large surface/volume ratio and the engineered characteristic's such as, permeability, stability, and porosity ${ }^{1}$. Core@shell nanostructures have been a dynamic area of research for their tailored multifunctional properties arising as a result of the existence of two or more nanostructure phases of different materials with one forming the shell on the surface of the other ${ }^{2-7}$. In the current work we have studied the core@shell nanostructure of $\mathrm{NiZnFe}_{2} \mathrm{O}_{4} / \mathrm{CdS}$, which is a ferromagnetic/diamagnetic core@shell system. The core material chosen was $\mathrm{NiZnFe}_{2} \mathrm{O}_{4}$ which is a soft ferrite. The reason to opt soft ferrite is there properties such as high resistivity which means "low eddy current loss" and "high usable frequency" ranges, "high magnetic permeability" which means high induction in smallest space, adaptability of shape of the core which persuade magnetic requirements in nominal space and their light-weight and low-cost relative to other materials. In our core@shell system the well-controlled interface between the two components give rise to exciting properties due to the presence of two different components at the surface. This ferromagnetic/diamagnetic system of core@shell nanostructures has been studied using various methods.

Magnetic properties of the core and the interface in core@shell nanostructure have been studied using vibrating sample magnetometry measurements (VSM) at room temperature. Optical studies were performed using UV-visible spectroscopy and Photoluminescence spectroscopy at room temperature. HRTEM images give the straightforward proof for the formation of core@shell nanostructure and the formation of sharp interface between two components. "The coherency strain, which allows the shell substantial at the interface to fine-tune the lattice parameters of the core, can play an important role in such core@shell nanostructure systems ${ }^{8}$. These magneto-fluorescent nanostructures can be used in various applications such as spintronics; as-well-as for drug delivery-diagnosis-imaging applications in the field of nanomedicine $e^{7,9-11}$. 

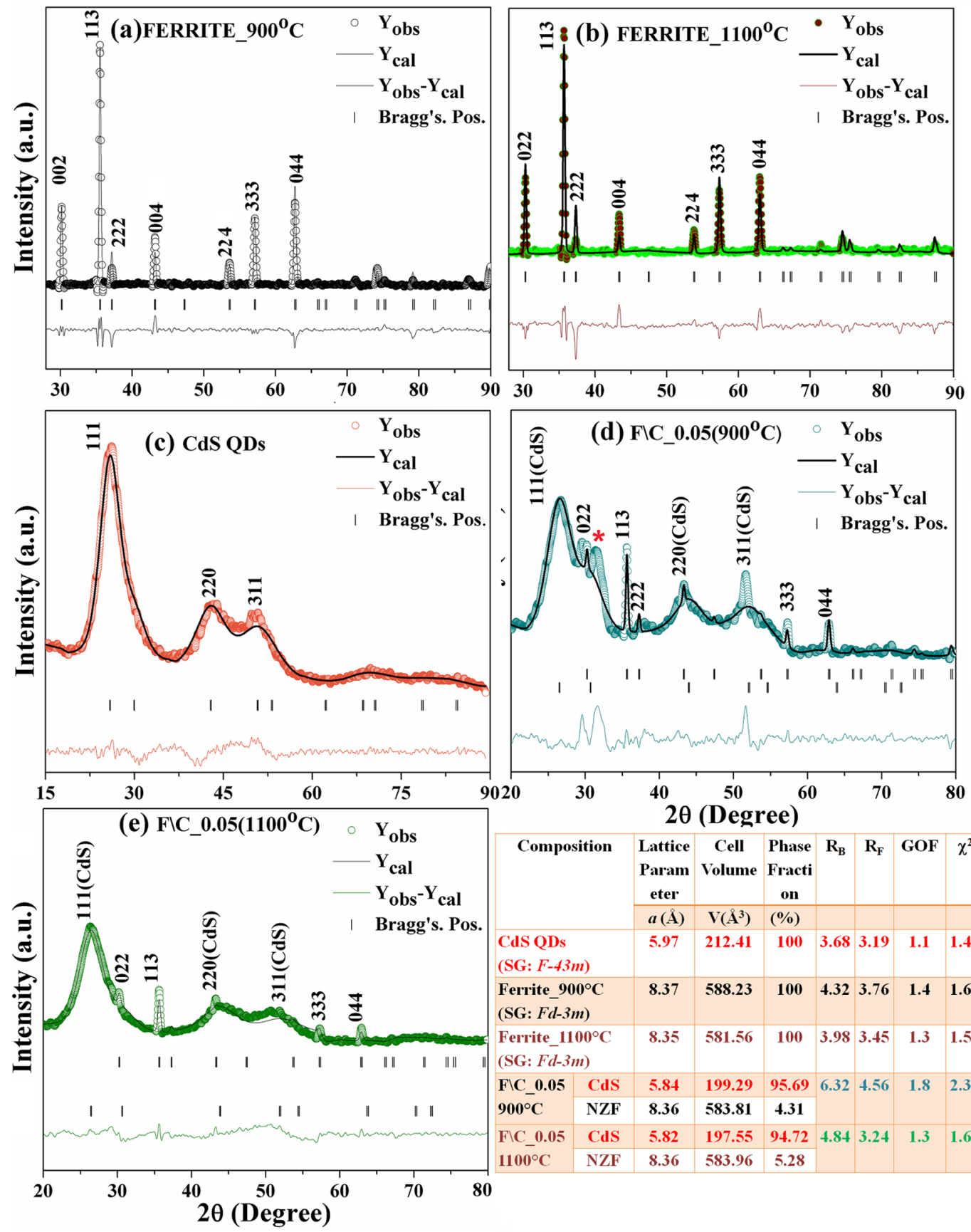

$2 \theta$ (Degree)

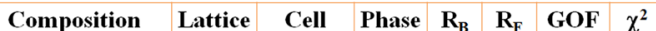
Param Volume Fracti

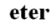
\begin{tabular}{l|l} 
eter & on \\
\hline$a(\mathrm{~A})$ & $\mathrm{V}\left(\mathrm{A}^{3}\right)(\%)$ \\
\hline
\end{tabular} $\begin{array}{lll}a(\AA) & \mathbf{V}\left(\AA^{3}\right) & (\%)\end{array}$

CdS QDs

Ferrite $900^{\circ} \mathrm{C}$ \begin{tabular}{|l|l|l|l|l|l|l|}
5.97 & 212.41 & 100 & 3.68 & 3.19 & 1.1 & 1.43 \\
\hline
\end{tabular}

(SG: $F d-3 m$ )

\begin{tabular}{|l|l|l|l|l|l|l|}
\hline Ferrite_1100 & & & \\
\hline
\end{tabular} (SG: $F d-3 m$ )

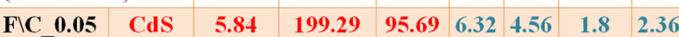

\begin{tabular}{|l|l|l|l|l|}
$\mathbf{9 0 0}^{\circ} \mathrm{C}$ & NZF & $\mathbf{8 . 3 6}$ & $\mathbf{5 8 3 . 8 1}$ & 4.31 \\
\hline
\end{tabular}

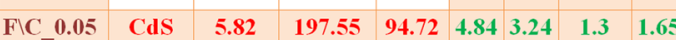
\begin{tabular}{|l|l|l|l|l|}
\hline $1100^{\circ} \mathrm{C}$ & NZF & $\mathbf{8 . 3 6}$ & $\mathbf{5 8 3 . 9 6}$ & $\mathbf{5 . 2 8}$ \\
\hline
\end{tabular}

Figure 1. The Rietveld refinement pattern of X-ray diffraction spectra for the (a,b) $\mathrm{NiZnFe}_{2} \mathrm{O}_{4}$; annealed at different temperatures (c) CdS QDs; and (d,e) $\mathrm{NiZnFe}_{2} \mathrm{O}_{4} / \mathrm{CdS}$ core@shell nanostructures.

\section{Results and Discussions}

Structural analysis. In the present study we have studied the X-ray diffraction spectrum for $\mathrm{NiZnFe}_{2} \mathrm{O}_{4}$ core, CdS QDs shell and core@shell nanostructures of $\mathrm{NiZnFe}_{2} \mathrm{O}_{4} / \mathrm{CdS}$ with core being annealed at two different temperature $900^{\circ} \mathrm{C}$ and $1100^{\circ} \mathrm{C}$ respectively as presented in Fig. 1(a-e). Peaks shown in XRD spectrum for $\mathrm{NiZnFe}_{2} \mathrm{O}_{4}$ annealed at $900^{\circ} \mathrm{C}$ (Fig. 1(a)) and $1100^{\circ} \mathrm{C}$ (Fig. 1(b)) have been indexed as (022), (113), (222), (004), (333), and (044) hkl planes indicating the formation of "single-phase spinel cubic structure" of nickel zinc ferrite (JCPDS No. 52-0277). The as-prepared nanoparticles do not exhibit any impurity phase. The intensity of the highest peak (113) is enhanced for the $1100^{\circ} \mathrm{C}$ annealed $\mathrm{NiZnFe}_{2} \mathrm{O}_{4}$ nanoparticles as compared to $900^{\circ} \mathrm{C}$ annealed $\mathrm{NiZnFe}_{2} \mathrm{O}_{4}$, showing better crystallinity. On increasing the annealing temperature of $\mathrm{NiZnFe}_{2} \mathrm{O}_{4}$ from $900^{\circ} \mathrm{C}$ to $1100^{\circ} \mathrm{C}$ the crystallite size was found to be decreased from $29.96 \mathrm{~nm}$ to $23.75 \mathrm{~nm}$ as calculated using Scherrer's formula. This decrease in crystallite size with increase in annealing temperature is due to increased micro strain ${ }^{12}$.

In CdS spectra (Fig. 1(c)) the peaks are indexed as (111), (220) and (311) hkl planes representing the cubic structure of CdS QDs (JCPDS No. 80-0019) with crystallite size approx. $1.83 \mathrm{~nm}$. Figure 1(d,e) shows the XRD 
spectra for the core@shell nanostructures with minimal $\mathrm{NiZnFe}_{2} \mathrm{O}_{4}$ loading of $0.05 \mathrm{~g}$. Diffraction peaks corresponding to $\mathrm{NiZnFe}_{2} \mathrm{O}_{4} / \mathrm{CdS}$ exhibited peaks both from the CdS QDs and for the $\mathrm{NiZnFe}_{2} \mathrm{O}_{4}$. Figure $1(\mathrm{~d})$ have an extra peak which is found to be of $\mathrm{ZnS}$ when confirmed through JCPDS card No. 05-0566. This trace of $\mathrm{ZnS}$ in case of core@shell nanostructure with $900^{\circ} \mathrm{C}$ annealed $\mathrm{NiZnFe}_{2} \mathrm{O}_{4}$ is due to intermixing of $\mathrm{Zn}$ present in ferrite with the sulphur used in CdS QD's synthesis. While in case of core@shell nanostructure with $1100^{\circ} \mathrm{C}$ annealed $\mathrm{NiZnFe}_{2} \mathrm{O}_{4}$ (Fig. 1(e)) there is no extra peak. Thus, we can say that at higher $\mathrm{NiZnFe}_{2} \mathrm{O}_{4}$ annealing temperature the core@shell system is more intact. This is an affirmative point for core@shell formation, where, there is no diffusion of core material with the shell and vice-versa. This point is further confirmed through optical and EDX results. Shift in the peaks was observed for all core@shell nanostructures on comparing with bare core and separate shell structures which confirms the successful formation of core@shell nanostructures. All the nanostructures were found to contain pure crystalline phases deprived of any type of alloying in the samples. Particle size calculation for core@shell nanostructures was not achievable by XRD because these spectra include distinct peaks for $\mathrm{NiZnFe}_{2} \mathrm{O}_{4}$ and CdS QDs. From the literature we have got the same trend of XRD spectra for different type of magnetic core and semionductor shell type core-shell nanostructures ${ }^{13-15}$. [More structural data for prepared nanostructures have been presented in Table 1 of Supplementary Data].

W-H plot for the $\mathrm{NiZnFe}_{2} \mathrm{O}_{4}$, CdS QDs and the $\mathrm{NiZnFe}_{2} \mathrm{O}_{4} / \mathrm{CdS}$ core@shell nanostructures (Supplementary Data Fig. 1) was used to find out more structural parameters. The attained values of the crystallite size from $\mathrm{W}-\mathrm{H}$ plot are comparable to those calculated using "Scherer's' formula. The crystallite size found to be $38.50 \mathrm{~nm}$ for ferrite annealed at $900^{\circ} \mathrm{C}, 30.80 \mathrm{~nm}$ for the ferrite annealed at $1100^{\circ} \mathrm{C}$ and $2.70 \mathrm{~nm}$ for CdS QDs. Strain estimated from Williamson-Hall ("W-H") method are also inscribed in figures. The positive slope of linear fit in the supplementary data Fig. $1(\mathrm{a}, \mathrm{c}, \mathrm{g})$ shows the tensile strain present in the sample. $900{ }^{\circ} \mathrm{C}$ annealed $\mathrm{NiZnFe}_{2} \mathrm{O}_{4}$ ferrite system (Supplementary Data Fig. 1(b)) is having very low value of strain i.e., 0.001 whereas $1100^{\circ} \mathrm{C}$ annealed $\mathrm{NiZnFe}_{2} \mathrm{O}_{4}$ has large micro-strain value of 2.62. CdS QDs posses 0.054 strain value, these results explain the effect of small particle size on higher strain values. In the core@shell nanostructures (Supplementary Data Fig. 1(d,e)) the negative slope is there and it indicates the compressive strain in the system, using this we can not calculate the particle size through W-H plot because the equation does not satisfied. Moreover, this result is one of the proof for core@shell formation. The negative slope of Supplementary Data Fig. 1(d,e) shows that macrostrains cannot be a leading source of broadening. Through these results it can be concluded that the effect of crystallite size and micro strains is negligible in the core@shell nanostructures.

The observed XRD spectra were refined by employing Rietveld refinement technique using the Full Prof software ${ }^{16,17}$. The corresponding calculated profiles (represented by solid black curve) and difference between observed and calculated profile (represented by the coloured line) have also been shown in Fig. 1. The lattice parameters (' $a$ ') obtained from Rietveld refinement in case of pure ferrite and in core@shell structure are in agreement with the experimental results and the values are close to the some of the previously reported values ${ }^{18,19}$. However, ' $a$ ' in case of pure CdS is found to be larger in comparison to core/shell structures this is because of the tensile stress present in pure CdS but as we grow CdS QDs on ferrite core there will be generation of compressive strain that gives the ' $a$ ' near to standard values. The experimental data (colour spectra) is well matched with the refined data points (black spectra) for the cubic CdS QDs, spinel cubic phase of $\mathrm{NiZnFe}_{2} \mathrm{O}_{4}$ and the two mixed phases of core@shell nanostructures, with the space group of $F-43 m$ for CdS QDs and $F d-3 m$ for $\mathrm{NiZnFe}_{2} \mathrm{O}_{4}$. The value of goodness of fit for all the samples was found to be near 1 which indicates toward the good fitting of data points. Rietveld refinement analysis ruled out the presence of any type of impurity in the nanostructures except in core/shell nanostructure where core has been annealed at $900^{\circ} \mathrm{C}$, have an extra peak which is found to be of $\mathrm{ZnS}$. Therefore the Rietveld parameters found weaker in this specific sample in comparison to other nanostructures specifically in comparison to other core@shell structure. In case of core@shell nanostructures mixed cubic faces of core and shell have been achieved. Summary of results obtained by Rietveld refinement analysis were collected in Fig. 1.

Absorbance spectroscopy. UV-visible spectrum for $\mathrm{NiZnFe}_{2} \mathrm{O}_{4}, \mathrm{CdS}$ QDs and their core@shell nanostructures have been recorded in order to study the optical behaviour of prepared structures (Fig. 2(a-d)) with different loadings of $\mathrm{NiZnFe}_{2} \mathrm{O}_{4}$. Figure 2(a) represents the absorbance spectra of $\mathrm{NiZnFe}_{2} \mathrm{O}_{4}$ prepared through annealing at $900^{\circ} \mathrm{C}$ and $1100^{\circ} \mathrm{C}$ and the graph clearly indicates no absorption behaviour in the range $350-800 \mathrm{~nm}$, which is of course the range of interest in order to prepare magneto-fluorescent structures. CdS QDs exhibits the band edge absorption at $379.60 \mathrm{~nm}$ and can be seen in the Fig. 2(b-d). In the core@shell nanoparticles with varied $\mathrm{NiZnFe}_{2} \mathrm{O}_{4}$ loadings, slight shift in absorption edge maxima has been observed (Fig. 2(b-d)) in case where core was annealed at $900^{\circ} \mathrm{C}$. "The variation in absorption edge was due to the introduction of synergistic effects of low absorption ferrite nanoparticles along with the high absorption CdS QD 20 ". The maximum $\mathrm{NiZnFe}_{2} \mathrm{O}_{4}$ loading $(0.2 \mathrm{~g})$ shows a shift in absorption toward lower wavelength side in case of core@shell nanostructures with $\mathrm{NiZnFe}_{2} \mathrm{O}_{4}$ being annealed at $900^{\circ} \mathrm{C}$ (Fig. 2(b)). Also, in case of core@shell nanostructures with $\mathrm{NiZnFe}_{2} \mathrm{O}_{4}$ being annealed at $1100^{\circ} \mathrm{C}$ the absorption edge slightly shifts to the blue side of the spectrum in comparison with the position of CdS QDs absorbance.

In the core@shell nanostructures with varying $\mathrm{NiZnFe}_{2} \mathrm{O}_{4}$ loading the absorption maxima at distinct positions have been obtained [Table 2 of Supplementary Data] and absorption is being shifted toward the blue side of the spectrum which signifies about the decrease in particle size of CdS QDs on shell formation over $\mathrm{NiZnFe}_{2} \mathrm{O}_{4}$ core. Moreover, there is lattice mismatch in the $\mathrm{NiZnFe}_{2} \mathrm{O}_{4}$ and CdS QDs structures eventually it produces compressive strain on the system, specifically in the CdS QDs as vindicated by the W-H plots of the core@shell nanostructures. Moreover, it is well known that there is relation between the increased strain in the system to the energy band gap and eventually to the particle size of the QDs ${ }^{21}$. Therefore, the obtained absorbance spectra of core@shell nanostructures clearly showcased the effect of increased strain via blue shifted absorbance profiles. 

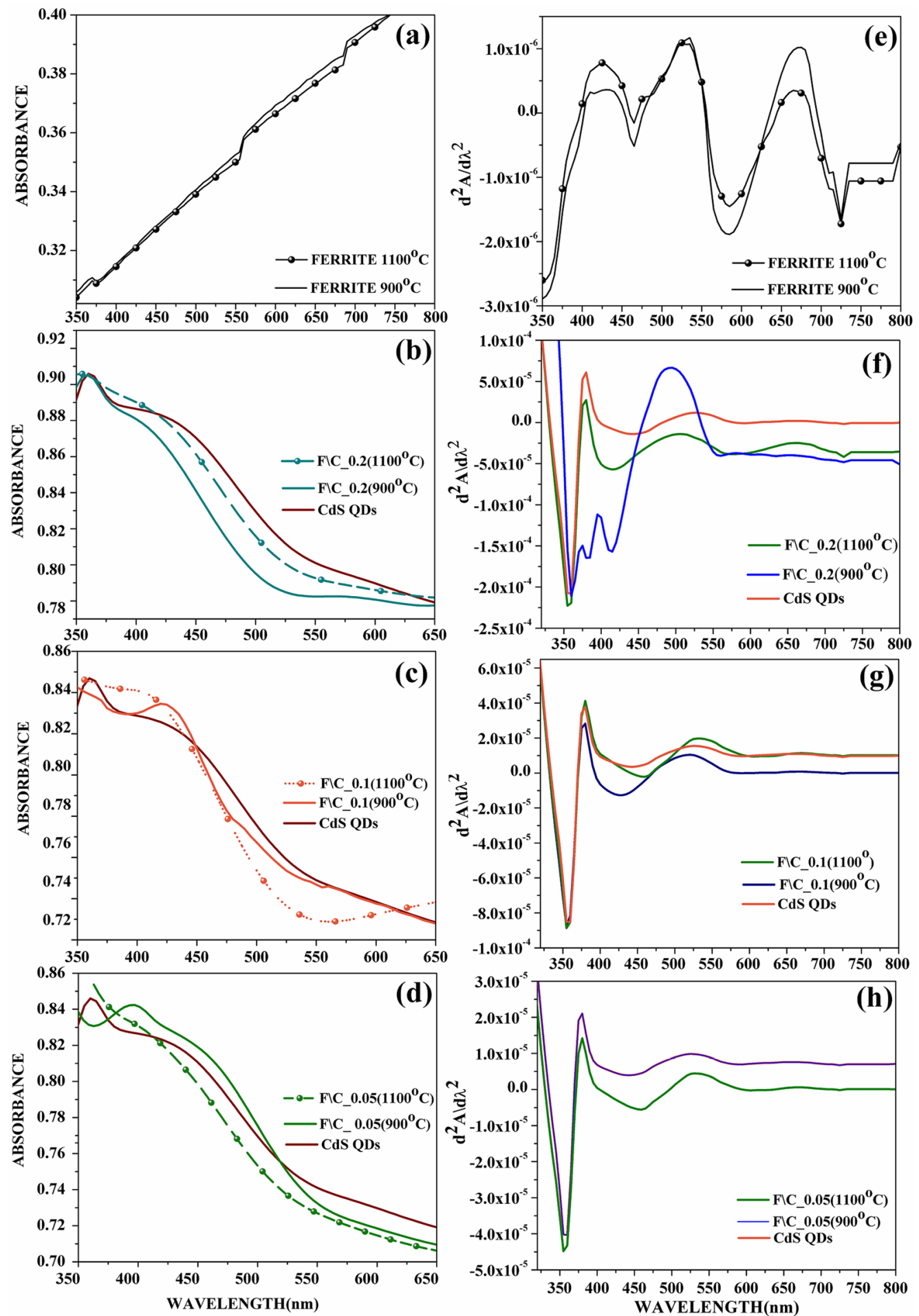

Figure 2. Absorbance spectra of (a) $\mathrm{NiZnFe}_{2} \mathrm{O}_{4} ; \mathrm{NiZnFe}_{2} \mathrm{O}_{4} / \mathrm{CdS}$ nanostructures (b) with $0.2 \mathrm{~g}$; (c) with 0.1 g; (d) with $0.05 \mathrm{~g}$ ferrite loading. Derivative absorbance spectra of (e) $\mathrm{NiZnFe}_{2} \mathrm{O}_{4}$; (f) $\mathrm{NiZnFe}_{2} \mathrm{O}_{4} / \mathrm{CdS}$ nanostructures with 0.2 g loading; $(\mathbf{g}) \mathrm{NiZnFe}_{2} \mathrm{O}_{4} / \mathrm{CdS}$ nanostructures with 0.1 g loading; (h) $\mathrm{NiZnFe}_{2} \mathrm{O}_{4} / \mathrm{CdS}$ nanostructures with $0.05 \mathrm{~g}$ loading.

Derivative spectroscopy (DS) uses either first or higher derivative of absorbance with reference to wavelength for qualitative analysis and quantification. "The impression of derivative spectra data was presented first in the 1950 s, when it was revealed to have many advantages $22-24$ ". If a spectrum is presented as absorbance "A", as a function of wavelength, " $\lambda$ ”, the derivative spectra will be:

$$
0^{\text {th }} \text { order, } A=f(\lambda) ; \quad I^{\text {st }} \text { order, } \mathrm{dA} / d \lambda=\mathrm{f}^{\prime}(\lambda) ; \quad \mathrm{II}^{\text {nd }} \text { order, } \mathrm{d}^{2} A / d \lambda^{2}=\mathrm{f}^{\prime \prime}(\lambda)
$$



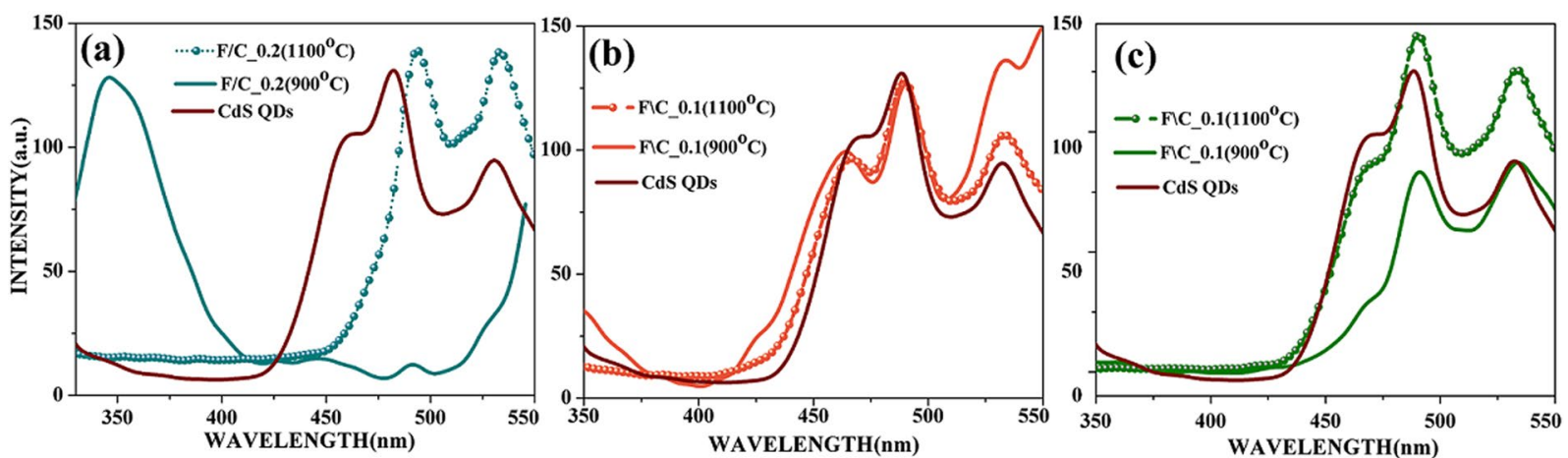

Figure 3. Photoluminescence spectra of (a) $\mathrm{NiZnFe}_{2} \mathrm{O}_{4} / \mathrm{CdS}$ nanostructures with 0.2 g loading; (b) $\mathrm{NiZnFe}_{2} \mathrm{O}_{4} /$ $\mathrm{CdS}$ nanostructures with $0.1 \mathrm{~g}$ loading; (c) $\mathrm{NiZnFe}_{2} \mathrm{O}_{4} / \mathrm{CdS}$ nanostructures with $0.05 \mathrm{~g}$ loading with respect to bare CdS QDs.

\begin{tabular}{|c|c|c|c|c|c|c|c|}
\hline \multirow[b]{2}{*}{ S. No. } & \multirow[b]{2}{*}{ Sample name } & \multicolumn{3}{|c|}{ Peak positions (nm) } & \multicolumn{3}{|c|}{ Intensities (a.u) } \\
\hline & & $\mathrm{E}_{1}$ & $\mathrm{E}_{2}$ & $\mathrm{E}_{3}$ & $\mathrm{I}_{1}$ & $\mathrm{I}_{2}$ & $\mathrm{I}_{3}$ \\
\hline 1. & CdS QDs & 460.2 & 482.3 & 530.5 & 106.7 & 130.0 & 125.0 \\
\hline 2. & $\mathrm{~F} \backslash \mathrm{C} \_0.2\left(900^{\circ} \mathrm{C}\right)$ & 345.6 & 491.0 & - & 128.9 & 20.1 & - \\
\hline 3. & $\mathrm{~F} \backslash \mathrm{C} \_0.2\left(1100^{\circ} \mathrm{C}\right)$ & 494.1 & 532.7 & - & 137.1 & 136.1 & - \\
\hline 4. & F\C_0.1 $\left(900^{\circ} \mathrm{C}\right)$ & 463.6 & 489.7 & 533.0 & 91.2 & 122.3 & 130.4 \\
\hline 5. & $\mathrm{~F} \backslash \mathrm{C} \_0.1\left(1100^{\circ} \mathrm{C}\right)$ & 464.0 & 489.0 & 533.9 & 90.0 & 122.3 & 98.5 \\
\hline 6. & FIC_0.05 $\left(900^{\circ} \mathrm{C}\right)$ & 466.7 & 490.4 & 533.5 & 33.1 & 83.4 & 87.9 \\
\hline 7. & $\mathrm{~F} \backslash \mathrm{C} \_0.05\left(1100^{\circ} \mathrm{C}\right)$ & 466.7 & 490.4 & 533.5 & 86.2 & 136.5 & 126.6 \\
\hline
\end{tabular}

Table 1. Summary of peak positions and intensities of CdS QDs and $\mathrm{NiZnFe}_{2} \mathrm{O}_{4} / \mathrm{CdS}$ nanostructures prepared with $0.2 \mathrm{~g}, 0.1 \mathrm{~g}$ and $0.05 \mathrm{~g}$ loading of $\mathrm{NiZnFe}_{2} \mathrm{O}_{4}$.

$\mathrm{I}^{\mathrm{st}}$ order derivative is calculated as the rate of change of absorbance with respect to wavelength it begins and ends at zero. The main trait of the even-order derivatives is a "strong negative" or "positive band" with maximum or minimum at the same wavelength as $\lambda_{\max }$, of the absorbance band. An important point to note is that the numbers of bands observed in spectra are always equal to the derivative order plus one. Figure $2(\mathrm{e}-\mathrm{h})$ shows the derivative of absorbance for the respective nanostructures. By using the second order derivative of absorbance for the respective samples we have calculated the exact absorbance positions for samples (Table 2 Supplementary Data). Figure 2(e-h) shows the second order derivative for the bare $\mathrm{NiZnFe}_{2} \mathrm{O}_{4}$, CdS QDs and their core@shell nanostructures. In the double derivative graphs three peaks are clearly seen in each case, which is the clear indication of second order derivation where the bands observed are equal to derivative order plus one. In case of $\mathrm{NiZnFe}_{2} \mathrm{O}_{4}$ Fig. 2(e) the three bands at almost same position have been observed. In case of core@shell nanostructures with $0.2 \mathrm{~g} \mathrm{NiZnFe}_{2} \mathrm{O}_{4}$ loading (Fig. 2(f)) some extra peaks are observed. Derivative spectra with core annealed at $900^{\circ} \mathrm{C}$ as compared to; pure $\mathrm{CdS}$ and core@shell nanostructure with $\mathrm{NiZnFe}_{2} \mathrm{O}_{4}$ annealed at $1100^{\circ} \mathrm{C}$ these extra peaks are due to some alloying of $\mathrm{NiZnFe}_{2} \mathrm{O}_{4}$ with $\mathrm{CdS}$ shell material and this band is due to $\mathrm{ZnS}$ formation during core@shell formation which has already been discussed in XRD results. Core@shell nanostructures with $\mathrm{NiZnFe}_{2} \mathrm{O}_{4}$ annealed at $1100^{\circ} \mathrm{C}$ give no such indication of alloying and give the peaks almost at the same position as obtained in CdS QDs. This shows that the core became more intact as the annealing temperature of core has been raised. In case of core@shell nanostructures with $0.1 \mathrm{~g}$ loading (Fig. 2(g)) some traces of intermixing are found in case of core@shell formed of $900^{\circ} \mathrm{C}$ annealed $\mathrm{NiZnFe}_{2} \mathrm{O}_{4}$ as can be seen from shifting in the peaks. This alloying is completely eliminated in case of core@shell nanostructures with minimal $\mathrm{NiZnFe}_{2} \mathrm{O}_{4}$ loading $(0.05 \mathrm{~g})$ (Fig. 2(h)) where all the CdS QDs, $\mathrm{NiZnFe}_{2} \mathrm{O}_{4} / \mathrm{CdS}\left(900^{\circ} \mathrm{C}\right)$ and $\mathrm{NiZnFe}_{2} \mathrm{O}_{4} / \mathrm{CdS}\left(1100^{\circ} \mathrm{C}\right)$ bands positioned similarly (no shifting) and also presenting no presence of extra peak.

Photoluminescence study. Room temperature photoluminescence spectra of CdS QDs along with different core@shell nanostructures of $\mathrm{NiZnFe}_{2} \mathrm{O}_{4} / \mathrm{CdS}$ were recorded by dispersing the $0.02 \mathrm{mg} / \mathrm{ml}$ sample in the water and are shown in Fig. 3. The PL spectra of entire $\mathrm{NiZnFe}_{2} \mathrm{O}_{4} / \mathrm{CdS} 2$ core@shell nanostructures and CdS2 QDs have been recorded with the excitation wavelength of $290 \mathrm{~nm}$. Corresponding emission wavelengths and intensities of the peaks observed in PL for all the nanostructures have been summarized in Table 1. Fluorescence spectra of CdS QDs were observed with intense emission band as compared to their core@shell nanostructure which includes magnetic nanoparticles. A high intensity band was obtained at $482.2 \mathrm{~nm}$ which was due to de-trapped charge carrier recombination. A weak band at $530.5 \mathrm{~nm}$, attributed to recombination of trapped electrons and holes present at the surface defect sites was also observed. However, the PL dynamics of CdS QDs is distinctly different from that of the $\mathrm{NiZnFe}_{2} \mathrm{O}_{4} / \mathrm{CdS}$ nanostructures with different loading of $\mathrm{NiZnFe}_{2} \mathrm{O}_{4}$ core, in case of core@shell nanostructures with $0.2 \mathrm{~g}$ ferrite (annealed at $900^{\circ} \mathrm{C}$ ) loading (Fig. 3(a)) a very intense peak at $345 \mathrm{~nm}$ was found 
cps/ev

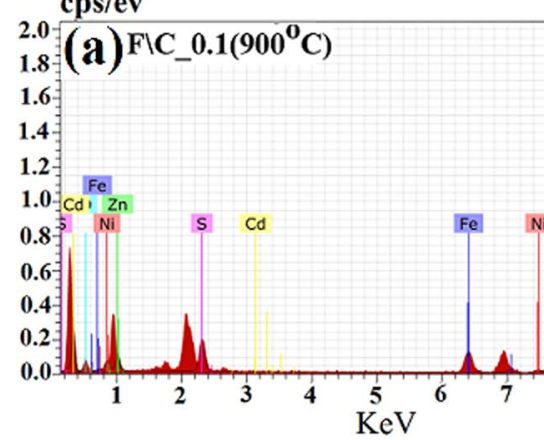

cps/ev

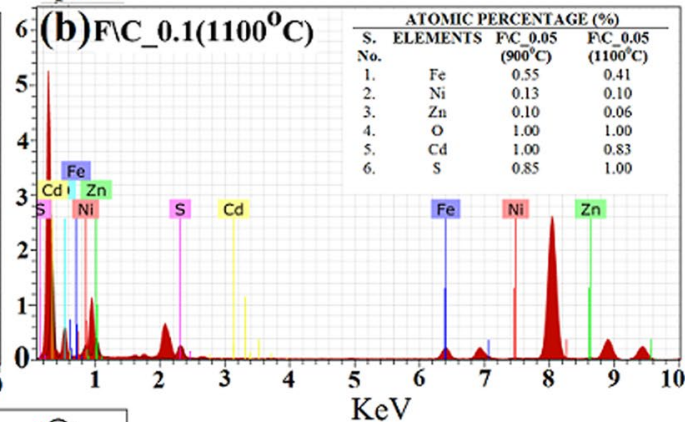

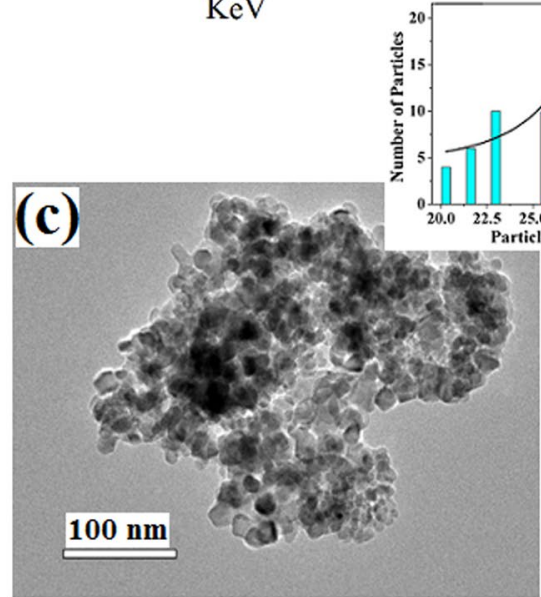
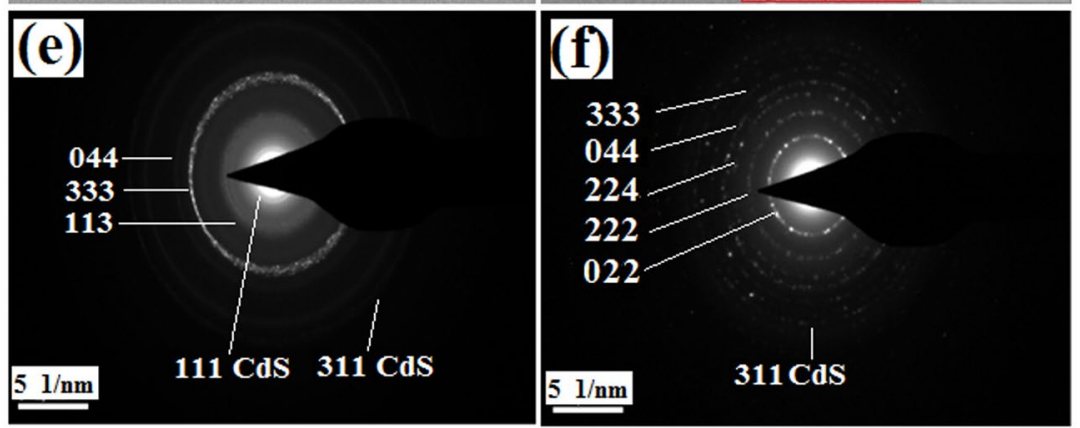

Figure 4. EDX spectra of core@shell nanostructures with (a) $0.05 \mathrm{~g}$ loading of $\mathrm{NiZnFe}_{2} \mathrm{O}_{4}\left(900^{\circ} \mathrm{C}\right)$; and (b) $0.05 \mathrm{~g}$ loading of $\mathrm{NiZnFe}_{2} \mathrm{O}_{4}\left(1100^{\circ} \mathrm{C}\right)$ with CdS2. TEM micrograph of core@shell nanostructures with (c) $0.05 \mathrm{~g}$ loading of $\mathrm{NiZnFe}_{2} \mathrm{O}_{4}\left(900^{\circ} \mathrm{C}\right)$; and $(\mathbf{d}) 0.05 \mathrm{~g}$ loading of $\mathrm{NiZnFe}_{2} \mathrm{O}_{4}\left(1100^{\circ} \mathrm{C}\right)$ with their respective SAD patterns $(\mathbf{e}, \mathbf{f})$.

and matched with $\mathrm{ZnS}$. The $\mathrm{ZnS}$ peak may be due to the presence of high amount of $\mathrm{Zn}$ present in $\mathrm{NiZnFe}_{2} \mathrm{O}_{4}$ to react with sulphur present in thiourea in the process of CdS QDs synthesis. This $\mathrm{ZnS}$ peak is also evident from the XRD analysis of core@shell nanostructures. This clearly indicates that $\mathrm{NiZnFe}_{2} \mathrm{O}_{4}$ annealed at $900^{\circ} \mathrm{C}$ is not very much stable as it releases the zinc present in ferrite to mix with sulphur of CdS. Thus, the $\mathrm{NiZnFe}_{2} \mathrm{O}_{4}$ annealed at $1100^{\circ} \mathrm{C}$ is much stable as compared to $900^{\circ} \mathrm{C}$ annealed $\mathrm{NiZnFe}_{2} \mathrm{O}_{4}$ as there is no leakage of $\mathrm{Zn}$ from NiZnFe $\mathrm{O}_{4}$ to CdS QDs shell. While in case of $\mathrm{NiZnFe}_{2} \mathrm{O}_{4}$ loading of $0.1 \mathrm{~g}$ (Fig. 3(b)) and $0.05 \mathrm{~g}$ (Fig. 3(c)) the $\mathrm{ZnS}$ peak is not present, better luminescent intensity and the better particle size distribution in case of minimal $\mathrm{NiZnFe}_{2} \mathrm{O}_{4}$ loading has been achieved (Fig. 4(c)). Therefore, this minimal ferrite loading has been opted out for further studies throughout the manuscript.

Energy-dispersive X-ray spectra and TEM. We have calculated the relative concentration of elements present in the EDX spectra. The EDX spectra of core@shell nanostructures $\left(900^{\circ} \mathrm{C}\right.$ and $\left.110^{\circ} \mathrm{C}\right)$ are being presented in (Fig. 4(a,b)). The stoichiometry ratios of prepared samples have been measured by EDX for elemental compositions in core@shell nanostructures with $\mathrm{NiZnFe}_{2} \mathrm{O}_{4}\left(900^{\circ} \mathrm{C}\right)$ and of $\mathrm{NiZnFe}_{2} \mathrm{O}_{4}\left(1100^{\circ} \mathrm{C}\right)$ with minimal ferrite loadings. The results revealed that the core@shell nanostructure prepared with $900^{\circ} \mathrm{C}$ (Fig. $4(\mathrm{a})$ ) annealed $\mathrm{NiZnFe}_{2} \mathrm{O}_{4}$ is off-stoichiometry, while prepared with $1100^{\circ} \mathrm{C}$ (Fig. $4(\mathrm{~b})$ ) annealed $\mathrm{NiZnFe}_{2} \mathrm{O}_{4}$ all the elements are found to be in expected compositional ratio. Availability of excess oxygen is due to the presence of oxygen in the formula of compound and in environment during characterization. The decrease in sulphur content in case of $900^{\circ} \mathrm{C}$ annealed ferrite core as compared to $1100^{\circ} \mathrm{C}$ is due to the formation of $\mathrm{ZnS}$ in case of $900^{\circ} \mathrm{C}$ annealed core, which has also been evidenced from the XRD results and the optical study results. 
HR-TEM analysis has been used to analyse the shape and size of the synthesized core@shell nanostructures. Investigation of the core@shell nanostructures is done with samples containing minimal $\mathrm{NiZnFe}_{2} \mathrm{O}_{4}$ loading in the cases where core being annealed at $900^{\circ} \mathrm{C}$ and $1100^{\circ} \mathrm{C}$. Figure $4(\mathrm{c}, \mathrm{d})$ shows the HRTEM images of core@shell nanostructures. Before examination, the samples were ultrasonicated for $20 \mathrm{~min}$ in ethanol to avoid agglomeration. From Fig. 4(c,d) it is clearly seen that there are sharp interfaces in case of core@shell nanostructure prepared with $1100^{\circ} \mathrm{C}$ annealed $\mathrm{NiZnFe}_{2} \mathrm{O}_{4}$, as compared to $900^{\circ} \mathrm{C}$ annealed $\mathrm{NiZnFe}_{2} \mathrm{O}_{4}$ core. These sharp interfaces are due to the stability of core at high temperatures, which restricts the intermixing at the interface and we can see the clear black coloured core surrounded by the grey colour shell. Inset shows the zoomed image of core@shell nanostructures. The particle size distribution of core/shell nanostructures is also shown in Fig. 4 and it is in good agreement of XRD data of core and shell samples separately, and confirms the size of core/shell structures approximately $29 \mathrm{~nm}$ but it is not possible to find out the particle size from XRD results. HRTEM images also supports the structural and optical results where we have talked about the stability of core@shell nanostructures at higher annealing temperature. Figure $4(e, f)$ shows the indexed SAD pattern for nanostructures. These figures show the selected area electron diffraction pattern for the core@shell nanostructures with $\mathrm{NiZnFe}_{2} \mathrm{O}_{4}$ being annealed at two different temperatures. Both the patterns are showing the ring formation made up of small spots, every spot occurred from Bragg's reflection from a single crystallite which is the clear indication of poly-nanocrystalline nature of core@shell nanostructures.

Magnetic characterization. Magnetization measurements of $\mathrm{NiZnFe}_{2} \mathrm{O}_{4}$ annealed at two different temperatures $900^{\circ} \mathrm{C}$ and $1100^{\circ} \mathrm{C}$ and $\mathrm{NiZnFe}_{2} \mathrm{O}_{4} / \mathrm{CdS}$ core@shell nanoparticles have been measured. The magnetic hysteresis loop for core and core@shell nanostructures is illustrated in Fig. 5(a-d), there was no need to perform the VSM analysis of shell CdS QDs as these are purely diamagnetic in nature. The measured values for saturation magnetization $\left(M_{s}\right)$, retentivity $\left(M_{r}\right)$, coercivity $\left(H_{c}\right)$,) magnetic anisotropy $(K)$ and the magnetic moment $\left(\mu_{\mathrm{B}}\right)$ are listed in Table 2 . The saturation magnetization $\left(\mathrm{M}_{\mathrm{s}}\right)$ of $\mathrm{NiZnFe}_{2} \mathrm{O}_{4}$ core annealed at two different temperatures $900^{\circ} \mathrm{C}$ (Fig. 5(a)) and $1100^{\circ} \mathrm{C}$ (Fig. 5(a)) was found to be $70.16 \mathrm{emu} / \mathrm{g}$ and $66.35 \mathrm{emu} / \mathrm{g}$ respectively. The decrease in magnetization with increased annealing temperature is due to the excessive temperature which accelerates the ion-diffusion and formation of pores during annealing. As a result, the domain wall movement was not easy and may be the cause of decreased magnetization. Due to development of pores at higher annealing temperatures samples have the decrease in saturation magnetization. Moreover, samples experience an induced spin-reorientation transition, by a temperature change and reduced by an external magnetic field ${ }^{25}$.

In case of core@shell nanostructures with shell of CdS1, CdS2 and CdS4 at the room temperature the saturation magnetization was found to be in the range of $2.65 \mathrm{emu} / \mathrm{g} \sim 0.48 \mathrm{emu} / \mathrm{g}$ respectively (Fig. 5(c,d)). The saturation magnetization was decaying from pure ferrites to core@shell nanostructures; this is because of the non-magnetic CdS QDs shell formation over the $\mathrm{NiZnFe}_{2} \mathrm{O}_{4}$ core $^{26}$. Moreover, the phase fraction of ferrites (core) and CdS QDs (shell) from Rietveld analysis shows the reduced fraction of core ferrite and this is in the coordination with decay in saturation magnetization with core@shell formation and is another proof of the core@ shell formation. In spite of the decrease in magnetic nature of core@shell in $\mathrm{NiZnFe} \mathrm{O}_{4} / \mathrm{CdS}$, the well preserved coercivity in the core@shell nanostructure is an excellent sign for their bio-applications ${ }^{26}$. From the Table 2 it can be noted that there is the decreasing trend of anisotropy as we switch from pure $\mathrm{NiZnFe}_{2} \mathrm{O}_{4}$ to $\mathrm{NiZnFe}_{2} \mathrm{O}_{4} /$ CdS core@shell nanostructure this indicates about the intact core surface even after CdS QDs shell formation as if there is any increase in anisotropy it could result from the alloying of core@shell interface and can introduce adverse changes in the magnetic as well as optical properties of core@shell nanostructures. Moreover, Magnetic moment is calculated using the formula, $\mu \mathrm{B}=\left(\mathrm{M}_{\mathrm{W}} \times \mathrm{M}_{\mathrm{S}}\right) / 5585$, where $\mathrm{M}_{\mathrm{w}}$ is the molecular weight of compound and, $M_{S}$ is the magnetic saturation of respective sample. Variation of magnetic moment is tabulated in Table 2 and indicates the direct relation with magnetic saturation ${ }^{27}$. Moreover, the core@shell nanostructures prepared using $\mathrm{NiZnFe}_{2} \mathrm{O}_{4}$ core annealed at $1100^{\circ} \mathrm{C}$ which is the higher temperature is more stable and demonstrates the better suitability in terms of physical and chemical stability as seed material and hence possessing low anisotropy values. The coercivity values tend to decrease on increasing core ferrite loading, while the anisotropy values are decreasing with the increase of $\mathrm{NiZnFe}_{2} \mathrm{O}_{4}$ loading in the core@shell nanostructures prepared using $\mathrm{NiZnFe}_{2} \mathrm{O}_{4}$ $\left(1100^{\circ} \mathrm{C}\right)$ as core with varying CdS QD layers.

From the graphs Fig. 5(e-h) it is clearly seen that with decreasing the particle size of shell as CdS1, CdS2 and CdS4 (where $1 \mathrm{ml}, 2 \mathrm{ml}$ and $4 \mathrm{ml}$ concentration of 2-mercaptoethenol has been used as the surfactant to controlled growth of shell particles) the magnetic susceptibility and the magnetic saturation are decreasing. This decrease is related to the surface to volume ratio of the shell CdS QDs. As the particle is becoming small the band gap is increasing and hence the conductivity is decreasing and the shell starts becoming more diamagnetic. Therefore, the susceptibility is least in case of core@shell nanoparticles with shell formed of CdS4 as compared to other CdS QDs shells.

By solving the derivative of susceptibility, we can comment about the spin interaction of core@shell at the interface. From peak width we can get the information about the spin interactions. In case of core@shell nanostructures with maximum ferrite loading the peak position and the peak width are changing, in case of $900^{\circ} \mathrm{C}$ (Fig. 5(e)) annealed core $\mathrm{NiZnFe}_{2} \mathrm{O}_{4}$ there are major changes as compared to the $1100^{\circ} \mathrm{C}$ (Fig. $5(\mathrm{f})$ ) annealed $\mathrm{NiZnFe}_{2} \mathrm{O}_{4}$. Since we are only altering the particle size of shell keeping the ferrite loading fix, the change in peak position is due to the effect of shell on the core system. There may be some spin-spin interaction at the interface. In case of core@shell nanostructures with minimal $\mathrm{NiZnFe}_{2} \mathrm{O}_{4}$ loading of $0.05 \mathrm{~g}$, there is very negligible shift in both the set of samples (Fig. 5(g,h)). In the core@shell system of $900^{\circ} \mathrm{C}$ annealed core, there is negligible shift in peak position, but the susceptibility is decaying as the particle size of shell is decreasing. While in case of core@ shell nanostructures with $\mathrm{NiZnFe}_{2} \mathrm{O}_{4}$ being annealed at $1100^{\circ} \mathrm{C}$ both the peak position and the susceptibility are well maintained. Thus, we can say that prepared core@shell system is progressing towards more intactness and 

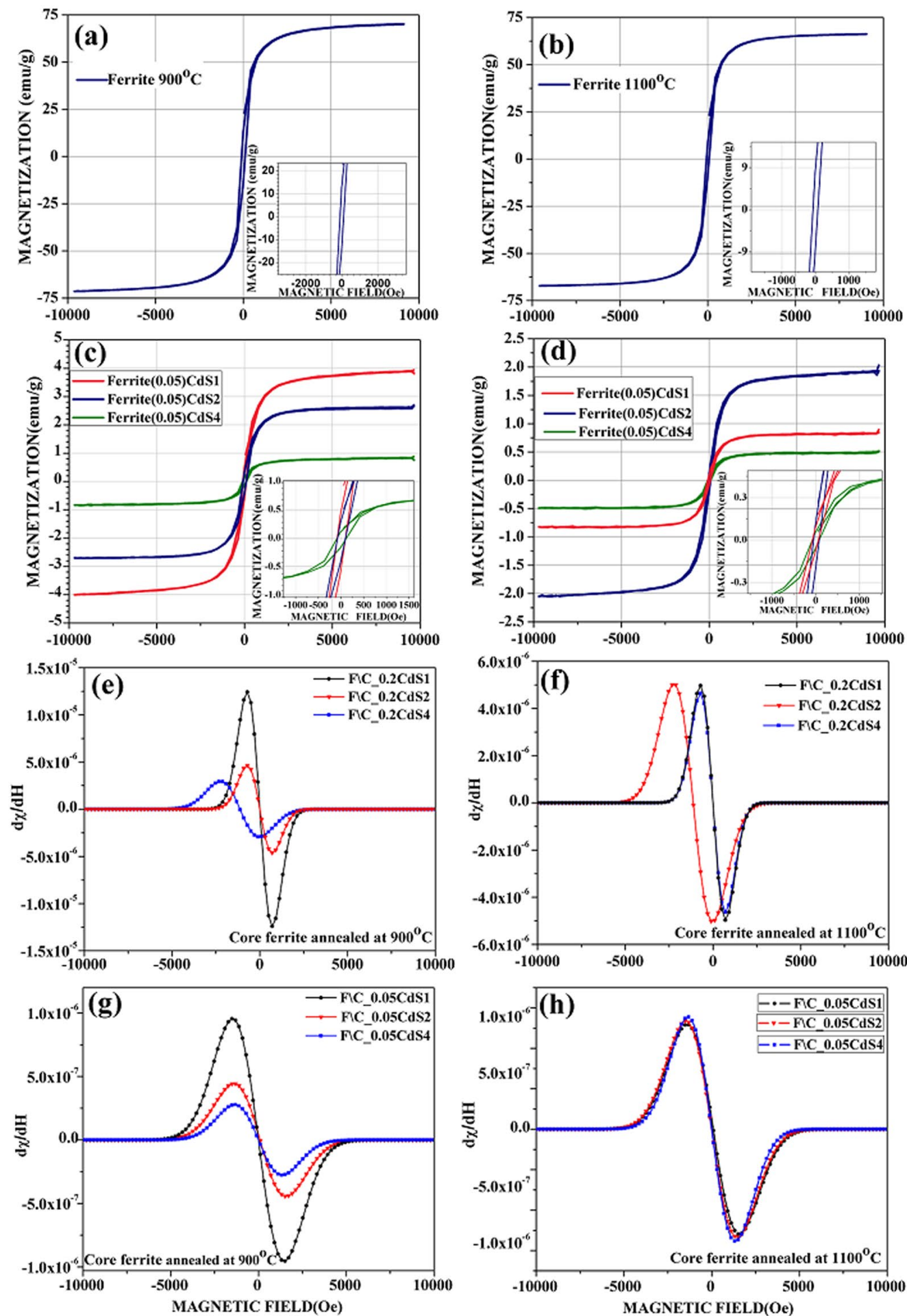

Figure 5. Hysteresis loops for $\mathrm{NiZnFe}_{2} \mathrm{O}_{4}$ (a) $900^{\circ} \mathrm{C}$, (b) $1100^{\circ} \mathrm{C}$; and $\mathrm{NiZnFe}_{2} \mathrm{O}_{4} / \mathrm{CdS}$ with $\mathrm{NiZnFe}_{2} \mathrm{O}_{4}$ (c) $900^{\circ} \mathrm{C}$, (d) $1100^{\circ} \mathrm{C}$; at room temperature with different particle sized shell. $\mathrm{d} \chi / \mathrm{dH}$ curves of $\mathrm{NiZnFe}_{2} \mathrm{O}_{4} / \mathrm{CdS}$ nanostructures with varying CdS QDs layers with $0.2 \mathrm{~g} \mathrm{NiZnFe} \mathrm{O}_{4}$ loading (e) $900^{\circ} \mathrm{C}$, (f) $1100^{\circ} \mathrm{C}$; and with 0.05 g NiZnFe ${ }_{2} \mathrm{O}_{4}$ loading (g) $900^{\circ} \mathrm{C}$, (h) $1100^{\circ} \mathrm{C}$.

stability at higher core annealing temperature and minimal core loading. Therefore, prepared sample can find many applications in biological field where best properties are needed at the cost of minimum amount of sample.

FTIR analysis. FTIR investigation was directed to recognize unknown materials as well as the number of components and the quality or consistency of our samples. Figure 6 shows the FT-IR spectra for nickel-zinc 


\begin{tabular}{|c|c|c|c|c|c|c|}
\hline S. No. & Sample & $\mathrm{M}_{\mathrm{s}}(\mathrm{emu} / \mathrm{g})$ & $\mathrm{M}_{\mathrm{r}}(\mathrm{emu} / \mathrm{g})$ & $\mathrm{H}_{\mathrm{c}}(\mathrm{Oe})$ & $\mathrm{K}\left(\mathrm{erg} / \mathrm{cm}^{3}\right)$ & $M_{\mu}(\mu B)$ \\
\hline 1. & FERRITE_900 ${ }^{\circ} \mathrm{C}$ & 70.16 & 13.04 & 98.98 & 3472.12 & 2.97 \\
\hline 2. & FERRITE_ $1100^{\circ} \mathrm{C}$ & 66.35 & 6.45 & 73.16 & 2427.02 & 2.81 \\
\hline 3. & FIC_0.05CdS1 $\left(900^{\circ} \mathrm{C}\right)$ & 3.91 & 0.44 & 91.00 & 177.90 & 0.27 \\
\hline 4. & FIC_0.05CdS1 $\left(1100^{\circ} \mathrm{C}\right)$ & 1.96 & 0.14 & 64.00 & 62.72 & 0.13 \\
\hline 5. & FlC_0.05CdS2 $\left(900^{\circ} \mathrm{C}\right)$ & 2.65 & 0.33 & 84.5 & 111.96 & 0.18 \\
\hline 6. & FIC_0.05CdS2 $\left(1100^{\circ} \mathrm{C}\right)$ & 0.81 & 0.08 & 69.00 & 27.94 & 0.06 \\
\hline 7. & FIC_0.05CdS4 $\left(900^{\circ} \mathrm{C}\right)$ & 0.82 & 0.12 & 98.50 & 40.38 & 0.06 \\
\hline 8. & FIC_0.05CdS4 $\left(1100^{\circ} \mathrm{C}\right)$ & 0.48 & 0.045 & 82.45 & 19.78 & 0.03 \\
\hline
\end{tabular}

Table 2. Magnetic parameters for $\mathrm{NiZnFe}_{2} \mathrm{O}_{4}$ and core@shell nanostructures.

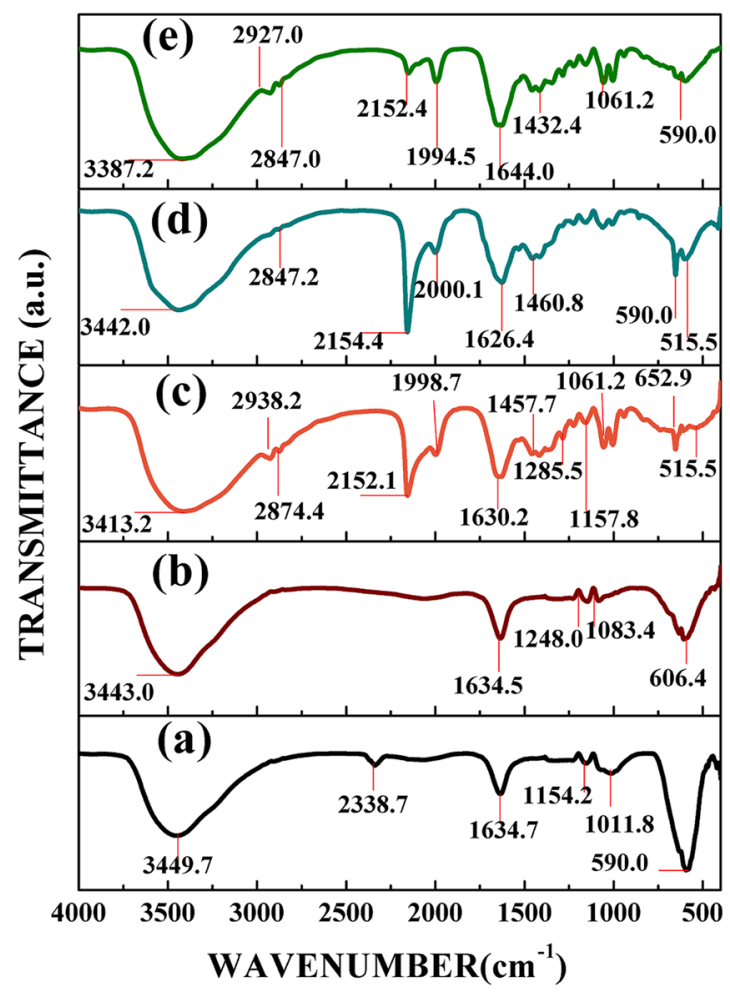

Figure 6. FTIR spectra of $\mathrm{NiZnFe}_{2} \mathrm{O}_{4}$ annealed at two different temperatures (a) $900^{\circ} \mathrm{C}$; (b) $1100^{\circ} \mathrm{C}$; (c) CdS QDs; and the core@shell nanostructures of $\mathrm{NiZnFe}_{2} \mathrm{O}_{4} / \mathrm{CdS}$ QDs prepared using ferrite annealed at two different temperatures $(\mathbf{d}) \mathrm{NiZnFe}_{2} \mathrm{O}_{4}\left(900^{\circ} \mathrm{C}\right) / \mathrm{CdS}$; and $(\mathbf{e}) \mathrm{NiZnFe}_{2} \mathrm{O}_{4}\left(1100^{\circ} \mathrm{C}\right) / \mathrm{CdS}$.

ferrite annealed at two different temperatures, CdS QDs, and the core@shell nanostructures of $\mathrm{NiZnFe}_{2} \mathrm{O}_{4} @ \mathrm{CdS}$. Ferrites, 2-mercaptoethanol capped CdS QDs and core@shell nanostructures were inspected through FTIR spectra in the range of $4000-400 \mathrm{~cm}^{-1}$. Figure $6(\mathrm{a}, \mathrm{b})$ shows the FT-IR spectra for pure ferrite annealed at $900^{\circ} \mathrm{C}$ and $1100^{\circ} \mathrm{C}$ respectively. In general, in the FTIR spectra of spinel ferrites two main broad oxygen metal bands have been observed which are also present in our samples. Therefore, the one, observed around $\nu_{1}=606 \mathrm{~cm}^{-1} \mathrm{corre}^{-}$ sponds to inherent stretching vibration of the metal ion at the "tetrahedral site", whereas the lowest band, that observed around $\nu_{2}=460 \mathrm{~cm}^{-1}$ is assigned to "octahedral" metal stretching vibration ${ }^{28}$. The band appearing near about at $3388 \mathrm{~cm}^{-1}$ corresponds to $\mathrm{O}-\mathrm{H}$ stretching vibration of $\mathrm{H}_{2} \mathrm{O}$; the special absorption peak at $2339 \mathrm{~cm}^{-1}$ corresponds to $\mathrm{O}-\mathrm{H}$ group of citric acid; the band at $1450 \mathrm{~cm}^{-1}$ was due to antisymmetric $\mathrm{NO}_{3}$ stretching vibrations and the band at $1647 \mathrm{~cm}^{-1}$ was due to carbo-oxalate anions $\mathrm{s}^{29-32}$. The stretching vibration at $2352 \mathrm{~cm}^{-1} \mathrm{cor}_{-}$ responds to the hydroxyl group. In Fig. 6 (c) the broad peak at $2120 \mathrm{~cm}^{-1}, 1383 \mathrm{~cm}^{-1}$ and the weak peak at 1614 $\mathrm{cm}^{-1}$ were assigned to $\mathrm{C}=\mathrm{C}, \mathrm{C}-\mathrm{H}$ characteristic vibrations in the $\mathrm{CdS}$ QDs samples. The band appearing near about at $3418 \mathrm{~cm}^{-1}$ corresponds to $\mathrm{O}-\mathrm{H}$ stretching vibration of $\mathrm{H}_{2} \mathrm{O}$, the stretching vibration at $2352 \mathrm{~cm}^{-1} \mathrm{cor}^{-}$ responds to the hydroxyl group.

These bands correspond to the mixture of the solution formed by metal nitrates and citric acid. The most attractive part of FTIR spectra, with respect to NiZn Ferrites, is in the range $800-250 \mathrm{~cm}^{-1}$. This range is dispensed to the ion vibrations in the crystal lattice. The $\nu_{1}$ band found between 800 and $500 \mathrm{~cm}^{-1}$, which is due to the stretching-vibrations occurred inside the tetrahedral sites. Another absorption $v_{2}$, is present in the middle of 450 and $300 \mathrm{~cm}^{-1}$. This band has been assigned to stretching-vibrations inside the octahedral sites. For all samples in Fig. 6, the analysis point out absorption peaks near about at $530 \mathrm{~cm}^{-1}$ corresponds to the $\mathrm{Fe}-\mathrm{O}$ vibration 
associated to the magnetite phase ${ }^{33}$. The results of the significant shift of $1634 \mathrm{~cm}^{-1}$ to $1630 \mathrm{~cm}^{-1}$ lower frequency indicates that the nanoparticles were in a closed-packed, crystalline state. In case of core@shell nanostructures (Fig. 6(d,e)) at some points we get the mixed peaks of both the ferrite and the CdS QDs.

\title{
Conclusion
}

- Demonstrated that the core@shell nanostructures of $\mathrm{NiZnFe}_{2} \mathrm{O}_{4} / \mathrm{CdS}$ can be synthesized successfully by seed mediate growth method having combination of sol-gel and solution growth methods.

- Structural analysis with the help of Rietveld refinement and; morphological characterizations depict the well-defined phases and high crystalline quality of $\mathrm{NiZnFe}_{2} \mathrm{O}_{4}$ core and CdS QDs shell.

- HR-TEM images and SAD pattern also confirms the core@shell nanostructure formation.

- CdS QDs shell was successfully employed upon the exterior of the Ni-Zn ferrite nanoparticles and a clear addition was observed in all the cases especially in minimal ferrite loading core@shell nanostructure.

- Optical studies discovered that the obtained nanostructures are stable and emit high intensity fluorescence and the best results were obtained at the minimal loading of core material.

- VSM investigation showed the formation of ferromagnetic $\mathrm{NiZnFe}_{2} \mathrm{O}_{4} / \mathrm{CdS}$ nanostructures.

- The spin dependent studies are performed on $\mathrm{NiZnFe}_{2} \mathrm{O}_{4} / \mathrm{CdS}$ nanostructures using derivative of susceptibility. In case of maximum amount of core loading and at lower annealing temperature of core ferrite it was found that the core@shell system formed has diffused boundaries, the spin-spin interaction of both the core and shell take place at the interface. While in case of minimal amount of core loading and at higher annealing temperature of core, core@shell system found to be more chemically and physically stable. Therefore, both core and shell are intact. Magnetic study also reveals that with semiconductor shell formation over magnetic core, saturation magnetization decays which is the clear indication of shell formation over core.

- FTIR studies divulged the functional groups present on the system are favourable to further process these magneto-fluorescent nanostructures for biomedical applications.

- Overall, findings suggest that these magneto-fluorescent nanostructures can be used in spintronics; as-well-as for drug delivery-diagnosis-imaging applications in the field of nanomedicine.

\begin{abstract}
Methods
Production of $\mathrm{NiZnFe}_{2} \mathrm{O}_{4} / \mathrm{CdS}$ core@shell nanostructures. We have employed the "seed growth method" to synthesise the core@shell nanostructure where $\mathrm{NiZnFe}_{2} \mathrm{O}_{4}$ was the core material upon which CdS QDs shell was grown using solution growth technique. Two different sets of core@shell nanostructure samples have been prepared by varying the annealing temperature of core, core loading and the particle size of CdS QDs shell formed over ferrite core. For the $\mathrm{NiZnFe}_{2} \mathrm{O}_{4}$ synthesis, we have mixed the stoichiometric ratios of nitrates according to their adjusted composition in the distilled water and the continuous stirring is applied until the nitrate solution completely dissolved in distilled water to form the solution of metal nitrates precursors. Metal nitrates precursors were then mixed in aqueous solution of citric acid monohydrates and the nitrate to citric acid molar ratio and maintained to $1: 3$. $\mathrm{pH}$ of the solution was adjusted to 7 by using ammonia solution. The reaction mixture was then heated at $75^{\circ} \mathrm{C} \pm 5^{\circ} \mathrm{C}$ with continuous stirring for several hours till the liquid solution changes to the viscous gel. The obtained gel was then dried at $110^{\circ} \mathrm{C}$ for $22 \mathrm{~h}$ in the hot air oven. Dried powder was then annealed at $900^{\circ} \mathrm{C}$ and $1100^{\circ} \mathrm{C}$ respectively for five hours to form $\mathrm{NiZnFe}_{2} \mathrm{O}_{4}$ nanoparticles. Henceforth, in direction of preparing $\mathrm{NiZnFe}_{2} \mathrm{O}_{4} / \mathrm{CdS}$ core@shell nanostructures, the as prepared $\mathrm{NiZnFe}_{2} \mathrm{O}_{4}$ nanoparticles annealed at two different temperatures were added as core (seeds) during the CdS QDs synthesis. The shell formation reaction which was employed in our synthesis mechanism consists of $\mathrm{CdCl}_{2}, \mathrm{NH}_{4} \mathrm{Cl}$, and thiourea in molar ratio of 1:1.5:3. Firstly, salts of ammonium chloride and cadmium chloride were added in $50 \mathrm{ml}$ of double distilled water with continuous stirring and heating. After that as the temperature reaches $70^{\circ} \mathrm{C} \pm 5^{\circ} \mathrm{C}$, ammonia solution was added drop wise to maintain the $\mathrm{pH}$ of solution 7.5, next as prepared $\mathrm{NiZnFe}_{2} \mathrm{O}_{4}$ was added and immediately after that thiourea and 2-mercaptoethanol were added. The reaction was continued for 3 hours with constant heating and stirring. Thereafter samples were cleaned and collected for further characterization. In the first set of samples we have synthesised the core@shell nanostructures with core annealed at $900^{\circ} \mathrm{C}$ and in the second set of samples core annealed at $1100^{\circ} \mathrm{C}$. The core loading was $0.02 \mathrm{~g}, 0.1 \mathrm{~g}$ and $0.05 \mathrm{~g}$ and the different sized particle shell formed using 2-mercaptoethanol solution in different amount as CdS1, CdS2, and CdS4 are the CdS QDs prepared by adding $1 \mathrm{ml}, 2 \mathrm{ml}$ and $4 \mathrm{ml}$ of $5 \% 2$-mercaptoethanol solution in the process of CdS growth.
\end{abstract}

Characterization methods. X-ray diffraction studies have been carried out using "Shimadzu 6000 diffractometer" equipped with $\mathrm{Cu}-\mathrm{K}_{\alpha}$ radiation within the scan range from $10^{\circ}-80^{\circ}$ with a scan speed of 2 degree/ minute, operated at " $40 \mathrm{kV}$ and $30 \mathrm{~mA}$ ". Rietvel refinement has been performed to study the crystal structure using FULLPROF A. Absorption spectra have been recorded in the wavelength range $200 \mathrm{~nm}$ to $800 \mathrm{~nm}$, using "Perkin Elmer Lambda 750 spectrophotometer". "LS-55 spectrophotometer (Perkin Elmer)" has been used to record "photoluminescence (PL) "spectra in the range 350-550 nm at an excitation-wavelength of $290 \mathrm{~nm}$ at room temperature. Magnetic measurements have been obtained using "PAR-155 vibrating sample magnetometer (VSM)" in the range " $-10 \mathrm{KOe}$ to $+10 \mathrm{KOe"} \mathrm{at} \mathrm{room} \mathrm{temperature.} \mathrm{High} \mathrm{resolution} \mathrm{transmission} \mathrm{electron} \mathrm{microscope}$ (HRTEM) and Energy Dispersive Spectroscopy (EDS) were carried by using "FP 5022/22-Tecnai G2 20 S-TWIN model". FT-IR analysis is done through "RX-IFTIR Perkin Elmer". 


\section{Data availability}

The datasets generated during and/or analysed during the current study are available from the corresponding author on reasonable request.

Received: 14 February 2019; Accepted: 4 October 2019;

Published online: 22 October 2019

\section{References}

1. Sahay, R., Reddy, V. J. \& Ramakrishna, S. Synthesis and applications of multifunctional composite nanomaterials. International Journal of Mechanical and Materials Engineering 9, 25 (2014).

2. Cho, N. H. et al. A multifunctional core-shell nanoparticle for dendritic cell-based cancer immunotherapy. Nature nanotechnology 6, 675 (2011).

3. Hao, R. et al. Synthesis, functionalization, and biomedical applications of multifunctional magnetic nanoparticles. Advanced Materials 22, 2729-42 (2010).

4. Kim, H., Achermann, M., Balet, L. P., Hollingsworth, J. A. \& Klimov, V. I. Synthesis and characterization of Co/CdSe core/shell nanocomposites: bifunctional magnetic-optical nanocrystals. Journal of the American Chemical Society 127, 544-6 (2005).

5. Vaidya, S., Kar, A., Patra, A. \& Ganguli, A. K. Core-Shell (CS) nanostructures and their application based on magnetic and optical properties. Reviews in Nanoscience and Nanotechnology 2, 106-26 (2013).

6. Wu, W., Jiang, C. \& Roy, V. A. Recent progress in magnetic iron oxide-semiconductor composite nanomaterials as promising photocatalysts. Nanoscale 7, 38-58 (2015).

7. Son, J. S., Lee, J. S., Shevchenko, E. V. \& Talapin, D. V. Magnet-in-the-semiconductor nanomaterials: High electron mobility in allinorganic arrays of $\mathrm{FePt} / \mathrm{CdSe}$ and $\mathrm{FePt} / \mathrm{CdS}$ core-shell heterostructures. The journal of physical chemistry letters 4, 1918-23 (2013).

8. Chen, X., Lou, Y., Samia, A. C. \& Burda, C. Coherency strain effects on the optical response of core/shell hetero nanostructures. Nano Letters 3, 799-803 (2003).

9. Chatterjee, K., Sarkar, S., Rao, K. J. \& Paria, S. Core/shell nanoparticles in biomedical applications. Advances in colloid and interface science 209, 8-39 (2014).

10. Issa, B., Obaidat, I., Albiss, B. \& Haik, Y. Magnetic nanoparticles: surface effects and properties related to biomedicine applications. International journal of molecular sciences 14, 21266-305 (2013).

11. Liu, E. et al. Investigation on spin dependent transport properties of core-shell structural Fe3O4/ZnS nanocomposites for spintronic application. Scientific Reports 5, 11164 (2015).

12. Nelson, P. I., Kannan, R. R., Mohan, A., Rajesh, S. \& Vidhya, B. Impact of sequential annealing on the characteristics of thermally evaporated semiconductor $\mathrm{Cu}_{2} \mathrm{Se} / \mathrm{ZnSe} / \mathrm{Cu}_{2}$ Se sandwich structure. Journal of Materials Science: Materials in Electronics 29, 7393-7401 (2018).

13. Abbas, M. et al. Highly stable-silica encapsulating magnetite nanoparticles $\left(\mathrm{Fe}_{3} \mathrm{O}_{4} / \mathrm{SiO}_{2}\right)$ synthesized using single surfactant lesspolyol process. Ceramics International 40, 1379-85 (2014).

14. Kale, A. et al. Magnetite/CdTe magnetic-fluorescent composite nanosystem for magnetic separation and bio-imaging. Nanotechnology 22, 225101 (2011).

15. Joseph, J., Mishra, N., Mehto, V. R., Banerjee, A. \& Pandey, R. K. Structural, optical and magnetic characterisation of bifunctional core shell nanostructure of $\mathrm{Fe}_{3} \mathrm{O}_{4} / \mathrm{CdS}$ synthesised using a room temperature aqueous route. Journal of Experimental Nanoscience 9 , 807-17 (2014).

16. Rodriguez, C. J. \& Fullprof, A. Reitveld refinement and pattern matching analysis program. Laboratory Leon Brillouin (CEA-CNRS) (2011).

17. Yogi, A. et al. Stripe order on the spin-1 stacked honeycomb lattice in $\mathrm{Ba}_{2} \mathrm{Ni}_{(}\left(\mathrm{PO}_{4}\right)_{2}$. Physical Review B 95, 024401 (2017).

18. Soltani, N., Gharibshahi, E. \& Saion, E. Band gap pf cubic and hexagonal CdS quantum dots- Experimental and theoretical studies. Chalcogenide Letters $9,321-328$ (2012).

19. Kumar, R., Kumar, H., Kumar, M., Singh, R. R. \& Barman, P. B. Enhanced saturation magnetization in cobalt doped Ni-Zn ferrite nanoparticles. Journal of Superconductivity and Novel Magnetism 28, 3557-3564 (2015).

20. Singh, C., Goyal, A., Malik, R., Bansal, S. \& Singhal, S. Envisioning the attachment of CdS nanoparticles on the surface of $\mathrm{MFe}_{2} \mathrm{O}_{4}$ $(\mathrm{M}=\mathrm{Zn}, \mathrm{Co}$ and $\mathrm{Ni}$ ) nanocubes: Analysis of structural, optical, magnetic and photocatalytic properties. Journal of Alloys and Compounds 695, 351-63 (2017).

21. Kuo, C. P., Vong, S. K., Cohen, R. M. \& String Fellow, G. B. Effect of mismatch strain on band gap in III-V semiconductors. Journal of Applied Physics 57, 5428-5432 (1985).

22. Bridge, T. P., Fell, A. F. \& Wardman, R. H. Perspectives in derivative spectroscopy Part 1, Theoretical principles. Journal of the Society of Dyers and Colourists 103, 17-27 (1987).

23. Kus, S., Marczenko, Z. \& Obarski, N. Derivative UV-VIS spectrophotometry in analytical chemistry. Chem. Anal. 41, 899-927 (1996).

24. Dixit, L. \& Ram, S. Quantitative analysis by derivative electronic spectroscopy. Applied Spectroscopy Reviews 21, 311-418 (1985).

25. Sangeetha, A., Kumar, K. V. \& Kumar, G. N. Effect of Annealing Temperature on the Structural and Magnetic Properties of $\mathrm{NiFe}_{2} \mathrm{O}_{4}$ Nano ferrites. Advances in Materials Physics and Chemistry 7, 19 (2017).

26. Saha, A. \& Viswanatha, R. Magnetism at the interface of magnetic Oxide and Nonmagnetic Semiconductor Quantum Dots. ACS Nano 11, 3347-54 (2017).

27. Srinivas, C. H. et al. Effect of $\mathrm{Ni}^{2+}$ substitution on structural and magnetic properties of $\mathrm{Ni}-\mathrm{Zn}$ ferrite nanoparticles. Journal of Magnetism and Magnetic Materials 382, 15-19 (2015).

28. De, M., Mukherjee, A. \& Tewari, H. S. Characterization of cadmium substituted nickel ferrites prepared using auto-combustion technique. Processing and Application of Ceramics 9, 193-197 (2015).

29. Shanmugavel, T., Raj, S. G., Kumar, G. R., Rajarajan, G. \& Saravanan, D. Cost effective preparation and characterization of nanocrystalline nickel ferrites $\left(\mathrm{NiFe}_{2} \mathrm{O}_{4}\right)$ in low temperature regime. Journal of King Saud University-Science 27, 176-81 (2015).

30. Waldron, R. D. Infrared spectra of ferrites. Physical review 99, 1727 (1955).

31. Grimes, N. W. \& Collett, A. J. Infrared absorption spectra of ferrites. Nature physical science 230, 158 (1971).

32. Nejati, K. \& Zabihi, R. Preparation and magnetic properties of nano size nickel ferrite particles using hydrothermal method. Chemistry Central. Journal 6, 23 (2012).

33. Mahdavi, M. et al. Synthesis, surface modification and characterisation of biocompatible magnetic iron oxide nanoparticles for biomedical applications. Molecules 18, 7533-7548 (2013).

\section{Acknowledgements}

I extend my sincere thanks to Jaypee University of Information Technology, Solan (H.P.) for providing the financial and infrastructural support. SAIF Panjab University Chandigarh, India for helping in recording XRD, IIT Roorkee, India for recording VSM results. 


\section{Author contributions}

R.R.S. conceived the idea and designed all the experiments. D.R. performed the experiments. D.R. and R.R.S. wrote the first draft of manuscript. P.B.B. checked the final manuscript. All authors read and approved the final manuscript.

\section{Competing interests}

The authors declare no competing interests.

\section{Additional information}

Supplementary information is available for this paper at https://doi.org/10.1038/s41598-019-51631-w.

Correspondence and requests for materials should be addressed to R.R.S.

Reprints and permissions information is available at www.nature.com/reprints.

Publisher's note Springer Nature remains neutral with regard to jurisdictional claims in published maps and institutional affiliations.

(c) (i) Open Access This article is licensed under a Creative Commons Attribution 4.0 International License, which permits use, sharing, adaptation, distribution and reproduction in any medium or format, as long as you give appropriate credit to the original author(s) and the source, provide a link to the Creative Commons license, and indicate if changes were made. The images or other third party material in this article are included in the article's Creative Commons license, unless indicated otherwise in a credit line to the material. If material is not included in the article's Creative Commons license and your intended use is not permitted by statutory regulation or exceeds the permitted use, you will need to obtain permission directly from the copyright holder. To view a copy of this license, visit http://creativecommons.org/licenses/by/4.0/.

(c) The Author(s) 2019 